\title{
Price transmission mechanism of transit service in city
}

\author{
GUANGLIN SUN ${ }^{1, a}$, JIAN WANG ${ }^{2, b}$ \\ ${ }^{1}$ School of Transportation Science and Engineering, Harbin Institute of Technology, Harbin, China \\ ${ }^{2}$ School of Transportation Science and Engineering, Harbin Institute of Technology, Harbin, China \\ amumulinhit@126.com, bwang_jian@hit.edu.cn
}

Keywords: transit price; transmission mechanism; transmission network

\begin{abstract}
Price transmission of transit service is a distinct mechanism with common characters. This paper aims to provide the nature and law of price transmission of transit service. The transmission of transit service prices is defined and transmission routes are classified into vertical and horizontal. The cost-push and demand-push are to drive the price carriers along transmission routes, which produces the price transmission network. Augmented Dickey-Fuller (ADF) and Granger co-integration test are used to measure the cost-push price transmission. For demand-push price transmission, the demand elasticity was used to model the relationship between transit demand and prices.
\end{abstract}

\section{Introduction}

The price transmission is defined to the intrinsic mechanism described by the price change due to price fluctuation of some products or service [1]. In addition, the coverage and degree of price transmission are depended on economic and policy environment [2]. The public transportation is indispensable infrastruction with semi-public goods property, and a global and fundamental service industry, determining the function of city. Therefore, the specific characteristics lead to the difference in transit price form and transit price transmission mechanism.

The public transport service is typical semi-public goods with production indivisibility, consumption separation, and enjoyment existing in consumption course. For this reason, the transit services are supplied by private or public department, and the services' price are formed according to market value rules and subsidized and controlled by government [3]. Hence the transit service prices simultaneously have common and specific characteristics as to the consequence of interaction among market, operator and government.

The research on price transmission mechanism may provide the means to stabilize public service price and adjust industrial structure. This paper is structured as follow: section 2 gives the definition and attributes of public transport price; section 3 provides the carrier, route and network of price transmission; the quantity to price transmission derived by cost and demand presents in section 4; section 5 concludes.

\section{The definition and attributes of price transmission}

(1) Definition

The price transmission is the process of price change of up-stream product effects on the price of down-stream product in term of industry chain relationship. Therefore, the price transmission of public transport can be defined as the price fluctuation mechanism due to cost, demand or some transit service price.

The price transmission mechanism is to exist in price operation of product or service and be affected by many factors. It relates to interior price or external environment by some way [4]. The transmission mechanism of public transport price includes three meaning:

1) the way of price transmission, including cost-push or demand-push;

2) the route of price transmission, including transmission chain and network;

3 ) the influence of many factors on price transmission. 
The price transmission of public transport occurs along to vertical and horizontal route under action of impact factors.

(2) Attributes

The attribute of semi-public product of public transport service promotes the government to a leading role, and presents the particularity of transmission way, route and factors.

1) the way of price transmission

In this paper, the way of price transmission can be classified into two kinds: cost-push and demand-push.

- cost-push

The nature attribute of cost-push is the effects of price change of up-stream products on the price of down-stream product. The up-stream product prices of public transport is related to transportation cost including energy, material and power etc., which to be as production factors whose value being transferred into the revenue of public transport service. When the transportation cost increasing, it must lead to the rise of operation cost, then the price will transmit along vertical direction if the public transport operator cannot internalize the factors of price rising.

- demand-push

The service provided by public transport has "congestion" attribute. When the number of passenger increasing beyond a threshold, congestion will occur and marginal cost is positive, which results in the decline of passengers utility with passengers growing. At this time, the rising of service price can improve the revenue of enterprise, as can supply the motivation and condition for more transportation service. Additionally, the change of service price can raise the share of public transport to gain new market equilibrium, when the contradiction between supply and demand appearing. The contradiction aroused by public transport demand is the power to promote the transport service price transmitting along horizontal direction due to the new equilibrium in transport service price system.

The mechanism of price transmission is objective law in price operation. However, the price change of up-stream product or demand cannot reflect absolutely at the service price in time, but the happening of price transmission is just time and degree problems.

2) the route of price transmission

According to price theory, the price system formed by organic connections among every kind of products and service price, performs the join of chain. It is general rule that the fluctuation of price of product and service at a link of chain will transmit to other link by cost-push or demand-push. The transmission chain of public transport price is promoted by transport cost-push and demand-push along vertical or horizontal direction. Assuming without external constrains, the public transport enterprise will be a receptor rather than a constitutor, and the efficiency of resource allocation will be distorted. The results lead to lost public welfare of public transport. Therefore, the government control to price formation and transmission route play a role in transmission direction and occurring.

3) the influence of many factors

The influencing factors may bring about the variability of transmission or transmission delay. Market general equilibrium aroused by change of a product or service price exists and the transmission of price change has no delay under perfect commodity economy condition. The formation of price and public vehicle operation may be influenced by government control, cost and demand etc. which generates the variation of price transmission.

\section{Transit price transmission mechanisms}

(1) cost-push price transmission

1) transmission carriers and routes

The prices of the fixed investments, energy, and raw materials and labor power are the origin of price transmission of general industrials chain, which can affect the price of industrial or semi-finished products and determine the price [5]. The providing of public transport service needs human resource including drivers, managers, service personals, and means of production such as fuel, 
vehicles etc. The means of products including metal, fuel and machine are from some semi-finished and finished products transformed from mineral resources, energy and raw materials. These productions are further processed into the elements needed in public transport operation. Therefore, the prices of mineral, energy etc. named up-stream products are important carriers in chain; the prices of fuel, vehicle etc. are the prices of medium-stream products; the price of public transport service is the price of down-stream products.

Hence, the cost-push price transmission can be represented as follow:

The prices of labor and products $\uparrow \rightarrow$ the prices of vehicle and fuel $\uparrow \rightarrow$ the price of public transport service; where all of the price transmission are positively related, and " $\uparrow "$ presents price rising. The vertical transmission route of public transport service price is represented in Figure 1:

\begin{tabular}{|c|c|c|}
\hline $\begin{array}{l}\text { the prices of labor } \\
\text { and products } \uparrow\end{array}$ & $\begin{array}{l}\text { the prices of vehicle } \\
\text { and fuel } \uparrow\end{array}$ & $\begin{array}{l}\text { the price of public } \\
\text { transport service } \uparrow\end{array}$ \\
\hline
\end{tabular}

Fig. 1 The cost-push price transmission route of public transport service

The vertical price transmission of public transport service is the reflection at operation cost with the price of up-stream products and further transmitting to the price of public transport service.

2) transmission network

The operation cost is the power to change the price and transmit along vertical route. Consequently, the price of public transport service reflects the price change of up-stream products. The transmission network formed by transmission routes is provided in Figure 2.

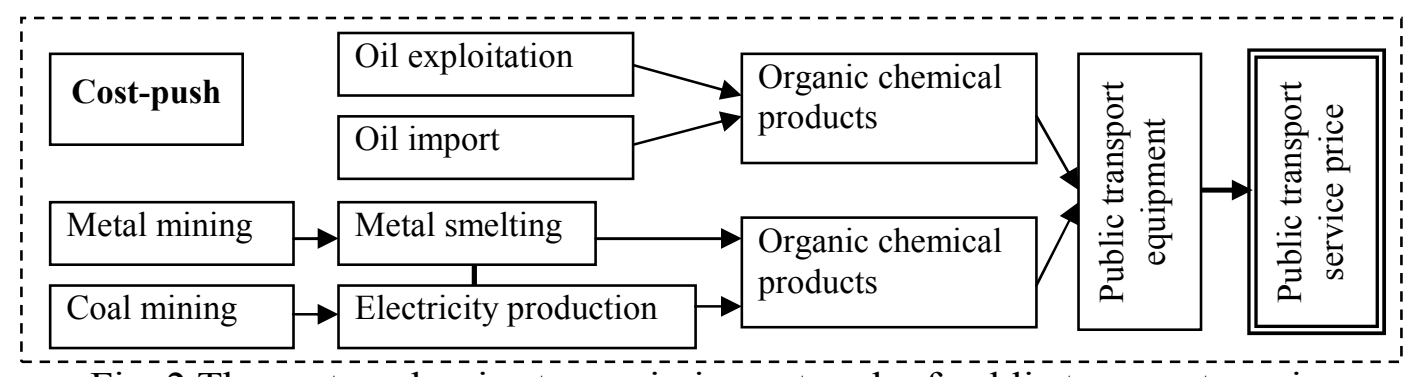

Fig. 2 The cost-push price transmission network of public transport service

(2) demand-push price transmission

1) transmission carriers and routes

Another power of price transmission is from the fluctuation of transit demand. One reason for demand fluctuation is the change of travel mode choice; the other is the policy effects on demand. The variation of mode share in public transport market may lead to congestion or idle of the usage of traffic resources, which can decrease the efficiency of public transportation. Therefore, the rational price is an efficient way to regulate transit demand; oppositely, the demand assignment can examine the rationality of price. In other words, the transit demand and service price are mutually carrier, and the transmission route is following.

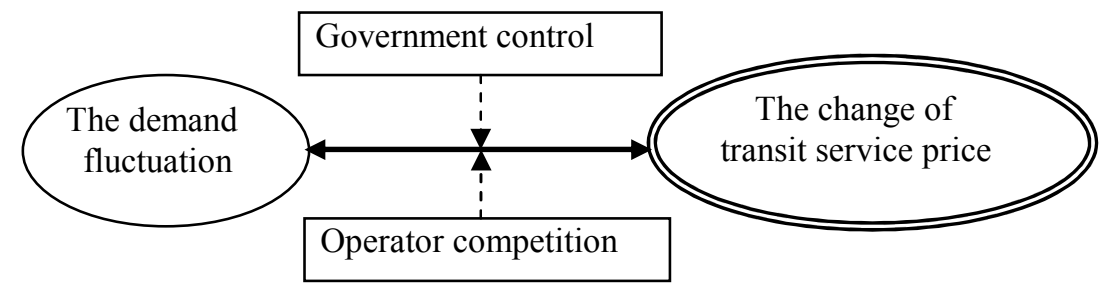

Fig. 3 The demand-push price transmission route of public transport service

2) transmission network

The variation of demand and cost is the power to price transmission along vertical and horizontal route, which reflects the price change of up-stream products. The transmission network formed by transmission network is presented in Figure 4. 


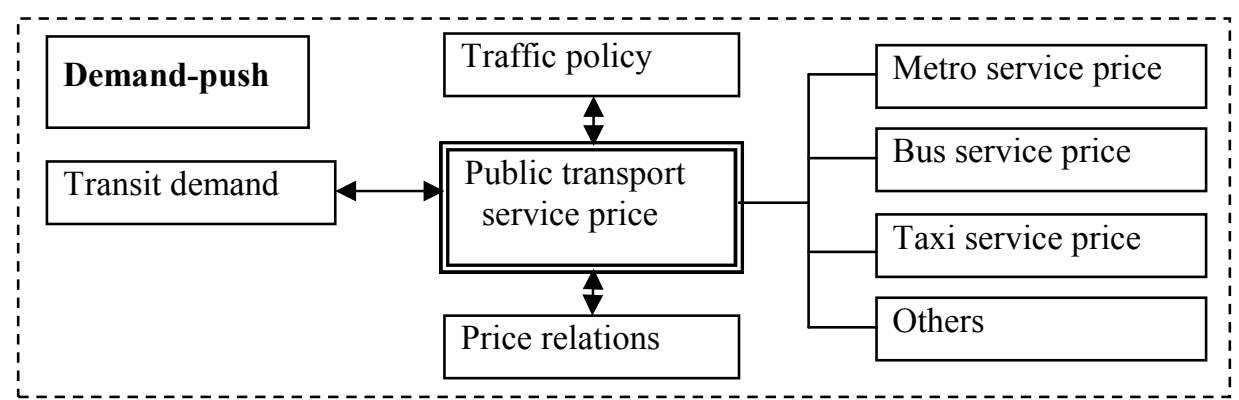

Fig. 4 The demand-push price transmission network of public transport service

(3) transmission results

Whatever the vertical or horizontal price transmission of up-stream products, it generates the price variation of public transport service (cost-push or demand-push). Under the condition for transit service prices as up-stream products and others as down-stream products, transit service prices will transmit to price system of public transportation along transmission routes. The price transmission of passenger transportation system is reported by Figure 5 .

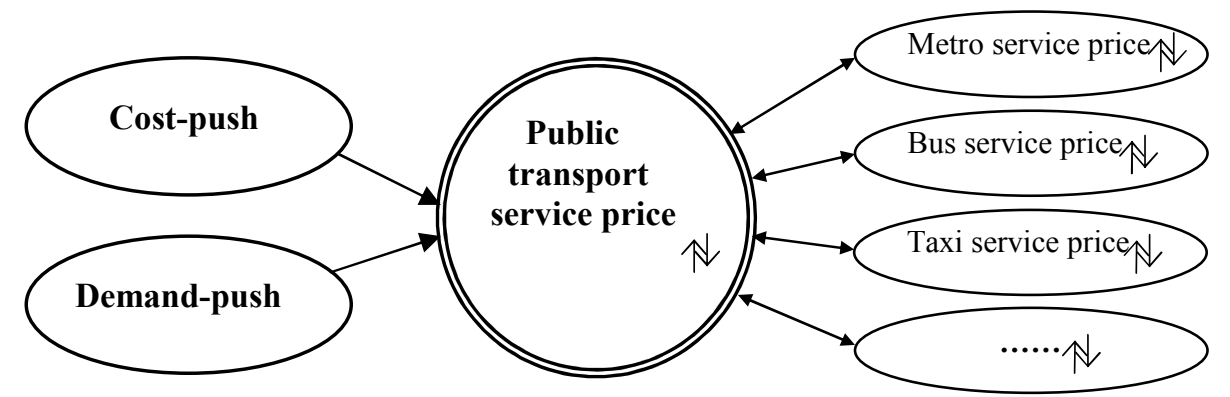

Fig. 5 The comprehensive price transmission network of public transport service

The price transmission is no longer successive as to the global and information market economy. The variation of cost or relationship between demand and supply may directly transmit from initiation to end without intermedium process. Therefore, keeping the public transport price steady needs enough government control.

\section{Transit price transmission pattern}

(1) cost-push price transmission

The cost-push is the nature of transit price transmission. For this reason, the regression model can be used to the stable price time series and Pearson coefficient model is adopted to calculate the correlation degree between price index at each link [6]. In this paper, the prices with no stable time series are analyzed by Augmented Dickey-Fuller (ADF) test and Johansen co-integration analysis base on co-integration theory proposed by Engle and Granger [7, 8, 9].

1) ADF test

The stable property of up-stream product prices and transit service prices must be examined before co-integration test. Firstly, both of the prices of up-stream products Pt and transit service prices Ft are treated into difference sequence $\Delta \mathrm{Pt}$ and $\Delta \mathrm{Ft}$ to do the unit root test for removing the time trend terms in order to satisfy stable series condition. These treatments can confirm the single whole order numbers of $\mathrm{Pt}$ and $\mathrm{Ft}$ when single whole order numbers of 2 series above are same, the co-integration correlation may be existing. The ADF model can be presented following.

$$
\Delta X_{t}=\alpha+\beta X_{t-1}+\sum_{i=1}^{n} \delta_{i} \Delta X_{t-i}+\varepsilon_{i}
$$

where $\Delta X_{t}=X_{t}-X_{t-1}, \Delta X_{t-i}=X_{t-i}-X_{t-i-1} ; X_{t}$ is the prices series of up-stream products when ADF test for up-stream products, otherwise $X_{t}$ presents the prices of public transport service. $\varepsilon_{t}$ is white noise; $n$ is delay periods. 
2) Johansen co-integration test

The VAR (Vector Auto Regression, VAR) is the basic model for Johansen co-integration test, which is reported as follow [8].

$$
\left[\begin{array}{l}
\Delta P_{t} \\
\Delta F_{t}
\end{array}\right]=\left[\begin{array}{l}
a_{1} \\
a_{2}
\end{array}\right]+\left[\begin{array}{cc}
\pi_{11}-1 & \pi_{12} \\
\pi_{21} & \pi_{22}-1
\end{array}\right]\left[\begin{array}{l}
P_{t-1} \\
F_{t-1}
\end{array}\right]+\left[\begin{array}{l}
u_{1 t} \\
u_{2 t}
\end{array}\right]
$$

where $a_{1}$ and $a_{2}$ are constants; $\pi_{11}, \pi_{12}, \pi_{21}, \pi_{22}$ are coefficients; $u_{1 t}$ and $u_{2 t}$ are random error terms;

Identifying the relationship between the prices of up-stream products and transit service prices must develop the binary model including Pt and Ft. Granger causal relationship model is following.

$$
\begin{aligned}
& P_{t}=a_{0}+\sum_{i=1}^{p} a_{i} P_{t-i}+\sum_{j=1}^{p} b_{j} F_{t-j} \\
& F_{t}=c_{0}+\sum_{i=1}^{p} c_{i} P_{t-i}+\sum_{j=1}^{p} d_{j} F_{t-j}
\end{aligned}
$$

If $b_{1}=b_{2}=\ldots=b_{p}=0, F$ is not the Granger reason for $P$, namely $F$ cannot explain and predict $P$; If $c_{1}=c_{2}=\ldots=c_{p}=0, P$ is not the Granger reason for $F$; if both of them are admitted, no causal relationship between them.

(2) demand-push price transmission

The transit demand elasticity can be used to describe demand-push price transmission. According to the principles of economics [10], the transmission relationship between public transport turnover $Q$ and service price $P$ can be indicated as follow $[11,12]$.

$$
Q=\alpha P^{\beta}
$$

where $\mathrm{Q}$ is public transport turnover (e 04 passengers $\cdot \mathrm{km}$ ); $\mathrm{P}$ is service price (yuan); $\alpha$ is constant; $\beta$ is coefficient of price elasticity of passenger turnover.

(3) transmission delay of transit service price

The price transmits without time delay under perfect market economics. The government can carry out enough controls to regulate the price of public transport service, such as public administration, industry policy etc. The variation of up-stream product prices may be neutralized and reversed the adverse impacts by tax, subsidy, special fund etc, as will produce the transmission delay. In other words, the variation of up-stream product prices has no reflection in down-stream transit service prices in time.

\section{Conclusions}

In this paper, we defined the transmission of transit service prices and provided the transmission attributes in way, route and impact factors. Presenting the carriers, routes and transmission network of transit service price, and developing the ADF test and multiple co-integration analysis method were to measure the cost-push price transmission. For demand-push price transmission, the demand elasticity was used to model the relationship between transit demand and prices. The law of price transmission can clear the correlations among departments of transit service, meanwhile provide theory basis for controlling the transit demand and supply equilibrium.

\section{References}

[1] Zhou Shuai, Yu Miao, The case study on price transmission mechanism, China Price, 2008, 9, pp. 9-12.

[2] Leng Shulian, Jiang Yejun, The analysis of price transmission mechanism, Price World, 2004, 12, pp. 10-13.

[3] Wang Jian, An Shi, Development and Experience from Toll Theory of Public Transport, Journal of Transportation Systems Engineering and Information Technology, 2004, 4(3), pp. 105-109.

[4] Wang Yongzhi, Some questions of price transmission mechanism, Price: Theory \& Practice, 2005, (2), pp. 10-13. 
[5] Sun Shengxiang, Li Zhenyu, Research on Conduction Mechanism of Naval Equipment Prices, JOURNAL OF WUT (INFORMATION \&MANAGEMENT ENGINEERING), 2008, 30(6), pp. 955-958.

[6] J Eggers, R Bauml, R Tzschoppe et al, Scalar Costa Scheme for Information Embedding, IEEE Trans on Signal Processing, 2003, 51, pp. 1003-1019.

[7] Engle R F, Granger C W J, Cointegration and error correction: representation, estimation and testing, Econometrica, 1987, 55, pp. 251-276.

[8] Johansen S, Statistical analysis of co-integration vectors, Journal of Economic Dynamic and Control, 1988, 12(2), pp. 231-254.

[9] Dickey D A, Fuller W A, Likelihood ratio statistics for auto regressive time series with unit root, Econometrica, 1981, 49, pp. 1057-1072.

[10]Alfred Marshall, Zhu Zhitai translate, Principles of economics, Beijing: The Commercial Press, 2005.

[11]Wang Dianhai, Wu Juan, Li Hongqiang, Study on Method of Deciding Bus Ticket Price for Typical Route, JOURNAL OF HIGHWAY AND TRANSPORTATION RESEARCH AND DEVELOPMENT, 2000, 17(6), pp. 10-12.

[12] Tong Yunhuan, Optimal Fare-Pricing for Urban Rapid-Transport Line Project and Government Compensation, System Engineering Theory \& Practice, 2001, (4), pp. 88-91. 